\title{
M.A.B. \\ Revestimientos vítreos con propiedades bactericidas y fungicidas
}

\author{
L. CUOGHI FENOLLAR' ${ }^{1}$, J. ROMERO VALIENTE ${ }^{1}$, C. VILLAR APELLANIZ1 ${ }^{1}$, V. FAUBEL SERRA ${ }^{2}$, \\ J.F. NOGUERA ORTÍ ${ }^{3}$, J. GARCÍA TEN ${ }^{3}$, A. YAGÜE MUÑOZ ${ }^{4}$, A.DURÁN $^{5}$ \\ ${ }^{1}$ TOGAMA,S.A. Ctra. Villarreal-Onda, Km.6. Villarreal, Castellón \\ ${ }^{2}$ Lic. Químico (Esp. Cerámica). Castellón \\ ${ }^{3}$ Instituto de Tecnología Cerámica (ITC). Asociación de Investigación de las Industrias Cerámicas (AICE). Universitat Jaume I. Castellón. España \\ ${ }^{4}$ FEA de S. de Microbiologia del Hospital de la Plana,Vila-real \\ ${ }^{5}$ Instituto de Cerámica y Vidrio (CSIC), Campus de Cantoblanco, Madrid, España
}

Este trabajo ha sido premiado con el Alfa de Plata en la Feria Internacional de Cerámica de Valencia CEVISAMA 2012

\begin{abstract}
La presente memoria describe el mosaico M.A.B. (bactericida y fungicida) de la empresa TOGAMA, S.A. perteneciente al grupo Fluidra S.A., el cual ha sido galardonado con el Premio Alfa de Plata que concede la Sociedad Española de Cerámica y Vidrio en la Feria Internacional de Cevisama 2012. Este galardón supone un reconocimiento al esfuerzo desarrollado en materia de investigación por parte de TOGAMA, S.A.,ya iniciado con la participación en los Premios Alfa de 2009 y 2011.
\end{abstract}

Palabras clave: Bactericida, Fungicida, M.A.B., mosaico.

M.A.B.

Vitreous coatings with bactericidal and fungicidal properties

This report describes the mosaic M.A.B. (bactericide and fungicide) produced by Togama S.A. belonging to the group Fluidra S.A., which has been awarded with the Silver Alfa Award by the Spanish Society of Ceramics and Glass at the International Fair Cevisama 2012. This award recognizes the R \& D efforts developed by Togama, SA, already started with participation in the Alpha Awards 2009 and 2011.

Keywords: Bactericide, Fungicide, MAB, mosaic.

\section{INTRODUCCIÓN}

En la actualidad, la salud pública es un tema de máxima actualidad. Las noticias sobre contaminación por microorganismos patógenos en zonas críticas, como hospitales, mataderos, restaurantes, instalaciones industriales, etc, crean alarma y preocupación en la sociedad. Por ejemplo, hace unos meses, una mutación de la bacteria E. coli provocó una grave infección en Alemania con graves efectos en la agricultura española. En Estados Unidos, una de cada 20 personas tiene riesgo de contraer una infección y morir. En las UCIs esta tasa aumenta a 1 de cada 4 personas. Michael Schmi$\mathrm{dt}$, que estuvo a cargo del ensayo clínico en cuatro centros de este país informa que, a diferencia de las noticias sobre accidentes de tránsito o incendios, los fallecimientos por infecciones intrahospitalarias raramente aparecen, siendo la cuarta causa de muerte en el mundo.

Entre estas infecciones ocupan también un lugar destacado las infecciones por hongos de diversos tipos, cuyos hábitats y temperaturas óptimas de desarrollo coinciden con los de muchos espacios hospitalarios como quirófanos y UVIs.
En los últimos años, las infecciones fúngicas han observado un curso ascendente. A su difusión ha contribuido el aumento del número de personas inmunodeprimidas (pacientes trasplantados, ancianos y enfermos de sida). En la mayoría de los casos, los hongos dan lugar a enfermedades benignas. Sin embargo, son cada vez más frecuentes las circunstancias donde los hongos resisten a los tratamientos y, en ocasiones, plantean una amenaza mortal a los infectados.

La alarmante situación ha llevado a los epidemiólogos a incluir a varios especímenes de hongos entre los patógenos emergentes, el grupo de microorganismos protagonistas del retorno de las infecciosas, junto con los virus y las bacterias resistentes a los medicamentos.

Entre los métodos para lograr el efecto antimicrobiano, destaca el efecto oligodinámico como método efectivo y conocido. La propiedad oligodinámica es la acción que ciertos iones metálicos tienen sobre los microorganismos, impidiendo su crecimiento (efecto bacteriostático), o eliminándolos (efecto bactericida). Varios iones metálicos tienen esta propiedad, 
incluida la plata, titanio, cobre, mercurio, cadmio, cromo, níquel, estaño, plomo, cobalto, zinc, hierro, manganeso, arsénico, antimonio, bismuto, bario y cerio.

Entre los métodos utilizados para la obtención de superficies cerámicas antimicrobianas se encuentran la aplicación de nanopartículas de dióxido de titanio $\left(\mathrm{TiO}_{2}\right)$ cuyo efecto se basa en sus propiedades fotocatalíticas. Pero el $\mathrm{TiO}_{2}$ fotocatalítico requiere la incidencia de radiación UV para mostrar propiedades bactericidas, por lo que sólo es útil en exteriores.

En el sector cerámico, se han realizado varios intentos de dotar a las baldosas de características antimicrobianas:

- Tichell y col. [1] describen una frita que contiene un óxido de tierras raras, que actúa como bactericida. Sin embargo, la propiedad bactericida sólo se manifiesta cuando el azulejo se ilumina con una radiación ultravioleta, con una longitud de onda entre 200 y $400 \mathrm{~nm}$.

- Jaquotot y col. [2] describen un esmalte nanoestructurado y multifuncional (bactericida, fungicida, autolimpiable,...) mediante la dispersión de nanopartículas sobre partículas matriz basadas en fibras de sepiolita. Sin embargo, no proporcionan ningún dato de eficacia bactericida ni ninguna norma utilizada para evaluar esta propiedad bactericida.

- Angiletto y col [3] describen un procedimiento de intercambio iónico para la obtención de un vidrio con propiedades bactericidas. Sin embargo, no hacen referencia a ningún procedimiento para la aplicación de este vidrio en la fabricación de baldosas cerámicas.

- $\quad$ Tucci y col [4] describen un procedimiento para preparar baldosas de gres porcelánico con propiedades antibacterianas mediante la adición de $\mathrm{Ag}_{2} \mathrm{O}$ en el soporte arcilloso. Sin embargo, el porcentaje de óxido de plata utilizado es muy alto, lo que implica un considerable aumento del coste de fabricación.

- $\quad$ La patente WO2008103621 [5] describe un procedimiento para la obtención de esmaltes bactericidas basados en el uso de $\mathrm{Ag}_{2} \mathrm{CO}_{3^{\prime}} \mathrm{Bi}_{2} \mathrm{O}_{3^{\prime}} \mathrm{CuO}, \mathrm{SnO}_{2^{\prime}}, \mathrm{TiO}_{2}$ y $\mathrm{ZnO}$, como agentes antimicrobianos. Sin embargo, estos esmaltes no son adecuados para los ciclos de monococción tradicionales utilizados en la industria de baldosas cerámicas.

- Las patentes US7488442 [6] y EP0808570 [7] describen procedimientos para la obtención de esmaltes bactericidas basados en el uso de plata. Sin embargo, el porcentaje de plata utilizado es muy alto, y en el caso de la patente EP0808570 los valores de eficacia bactericida son cualitativos y no hacen referencia a ninguna norma.

- La patente US2009117173 [8] describe un procedimiento para preparar esmaltes bactericidas mediante el uso de ZnO. Sin embargo, las composiciones señaladas no son aplicables al proceso de fabricación cerámico por las elevadas cantidades de $\mathrm{ZnO}$.
En resumen, los tratamientos antimicrobianos actuales no son satisfactorios. Por ello, TOGAMA se planteó la búsqueda de nuevas soluciones para que el producto final sea aceptable por el mercado.

\section{OBJETIVOS}

- Obtención de un mosaico vítreo con propiedades bactericidas y fungicidas, que no requieran la incidencia de radiación UV y por lo tanto se puedan utilizar tanto en exteriores como interiores (hospitales, mataderos, restaurantes, instalaciones industriales, guarderías, etc).

- Evaluar la eficacia bactericida del nuevo producto utilizando una norma de referencia a nivel internacional, la norma JIS Z 2801 (actualmente ISO 22196) y normas experimentales en acción fungicida (Centro de Investigaciones Biológicas - CSIC)

- Identificar y diferenciar el producto en el mercado mundial.

\section{PROCEDIMIENTO PROPUESTO}

El procedimiento propuesto consta de dos fases:

1. Efecto Bactericida.

2. Efecto Fungicida.

\subsection{Efecto Bactericida}

Uno de los hitos de este proyecto era conseguir una superficie bactericida, para ello debíamos conseguir que los principios activos estuvieran integrados en la fase vítrea de la tesela, pero quedando en superficie.

El valor de la eficacia antimicrobiana se determinó siguiendo el procedimiento descrito en la norma JIS Z 2801 (actualmente ISO 22196:2011) en un laboratorio de ensayo acreditado por ENAC (EN ISO 17025). La norma JIS Z 2801 ha sido adoptada a nivel internacional como norma de referencia para evaluar la eficacia antimicrobiana de superficies no porosas, cerámicas, plásticos, etc.

Según esta norma, la actividad antimicrobiana se determina comparando los resultados obtenidos entre la superficie tratada y una superficie control (blanco), después de un periodo de incubación de 24 horas a una temperatura óptima para el crecimiento del microrganismo seleccionado (Figura 1).

\subsection{Efecto Fungicida}

Partiendo de la hipótesis de que determinados cationes metálicos inhiben la proliferación de microrganismos, se propone incorporar estos cationes a diferentes composiciones de vidrios en el estado de oxidación con mayor actividad bactericida/fungicida.

El primer paso es diseñar y producir por fusión, vidrios en sistemas de silicato, borosilicato o borofosfosilicato, compatibles con la composición de las teselas, dopados con cationes metálicos. 
Estos vidrios se han preparado por fusión en horno de gas en condiciones oxidantes y se han dopado con cantidades variables de cationes.. Los vidrios se han caracterizado térmicamente estudiando el comportamiento de fluidez para su aplicación en el proceso actual, asegurando la compatibilidad térmica y química con el proceso de sinterización y con la matriz vítrea.

\section{RESULTADOS}

\subsection{Mosaicos con propiedades Bactericidas}

\subsubsection{MICROESTRUCTURA DE LAS SUPERFICIES}

El mosaico vítreo presenta una superficie formada mayoritariamente por fase vítrea y algunos cristales, que actúan como opacificante. En la Figura 2 se observan cristales de circón rodeados de fase vítrea (zona oscura).

La aplicación del principio activo generó una superficie en la que se observan partículas idénticas dispersas en toda la superficie de una manera homogénea. Figura 3.

\subsubsection{EFICACIA ANTIMICROBIANA}

La norma JIS Z 2801 define la actividad antimicrobiana de una superficie como la diferencia entre el número de bacterias en la muestra control (blanco) y el número de bacterias en la muestra tratada, según la ecuación (1).

$$
\mathrm{R}=\log \mathrm{B}-\log \mathrm{C}
$$

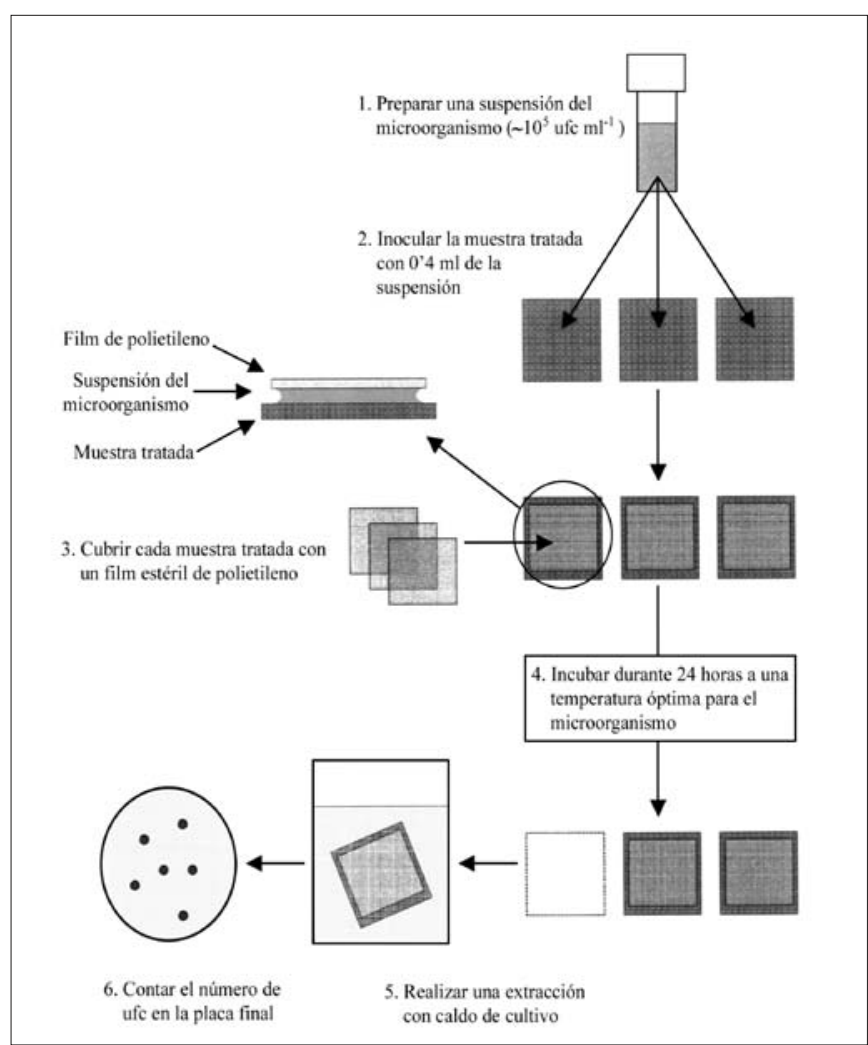

Figura 1. Representación gráfica del procedimiento descrito en la norma JIS Z 2801.

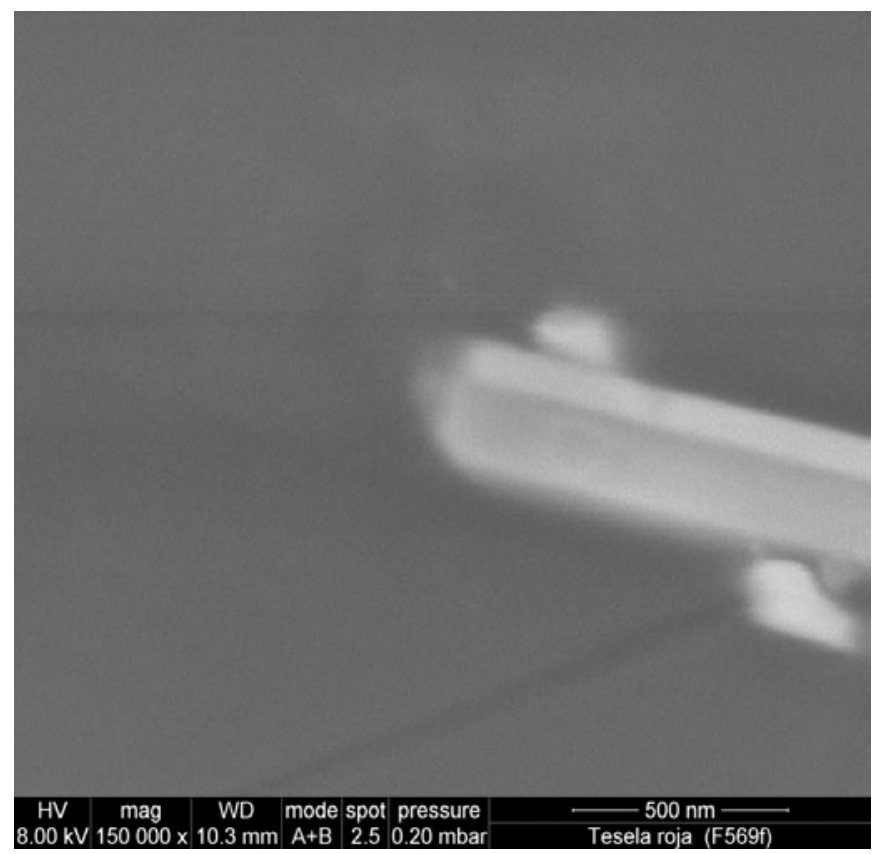

Figura 2. Superficie del mosaico vítreo.

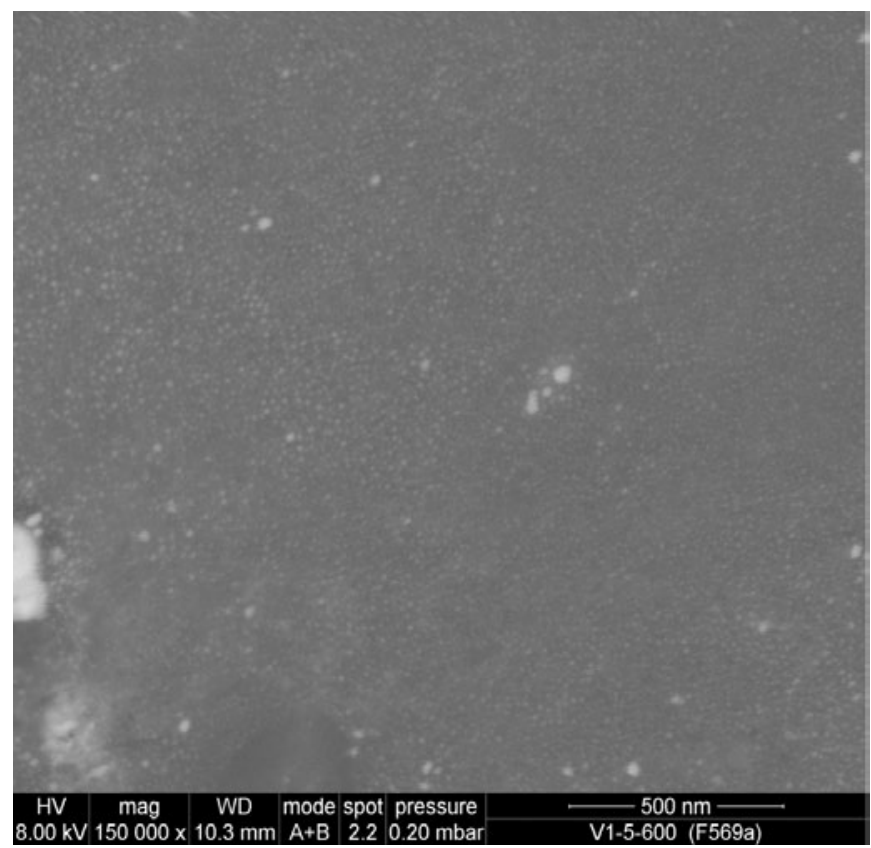

Figura 3. Superficie de la Muestra. 
A partir del número de ufc en las muestras tratadas y en las muestras control se calculó el valor de actividad antimicrobiana R según la ecuación (1).

En la Figura 4 y Figura 5 se muestra la disminución del número de unidades formadoras de colonia (ufc) por $\mathrm{mL}$ en las muestras tratadas, respecto a un blanco, que no presenta ningún tratamiento bactericida, después de 24 horas. Se puede observar una disminución muy acusada del número de ufc en las muestras tratadas, lo que indica la efectividad bactericida.

\section{Staphylococcus aureus}
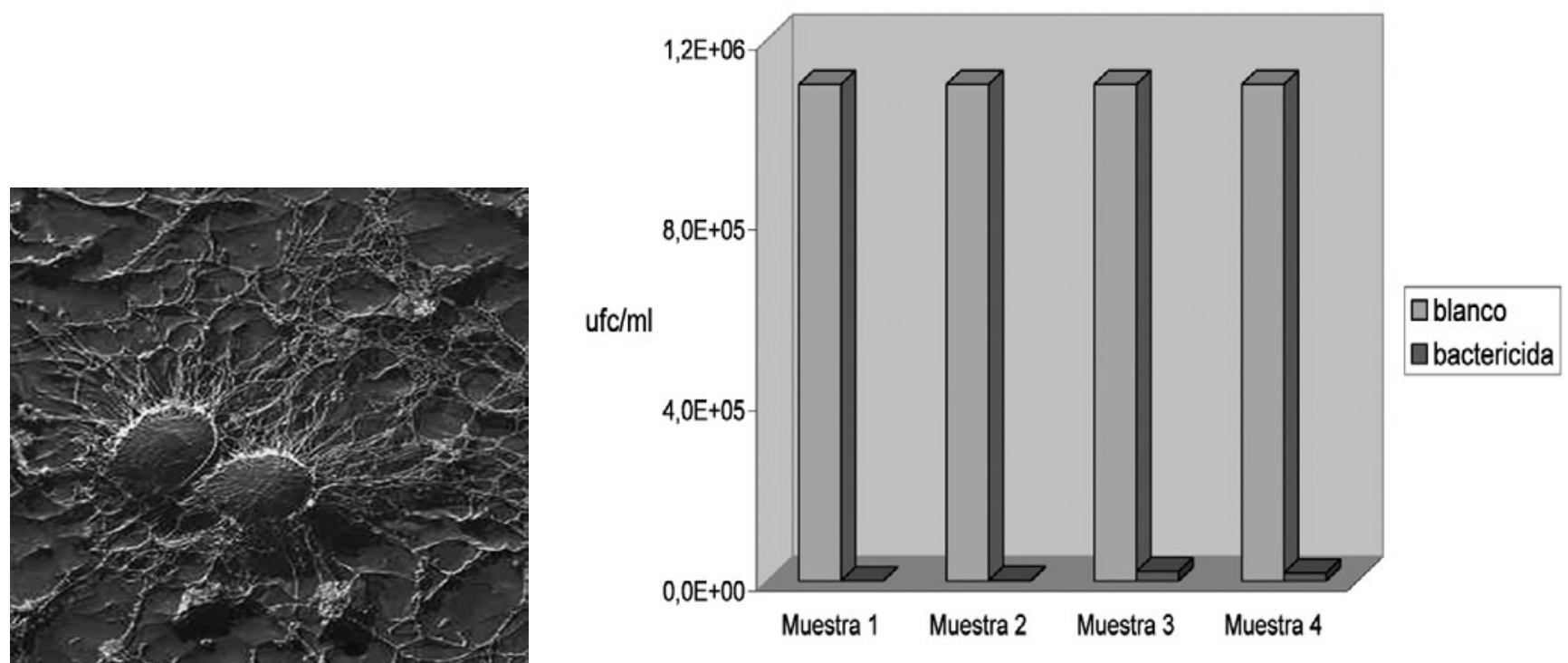

Figura 4. Número de ufc/ml en las muestras tratadas con respecto al blanco, para el microorganismo Staphylococcus aureus.

\section{Escherichis co}

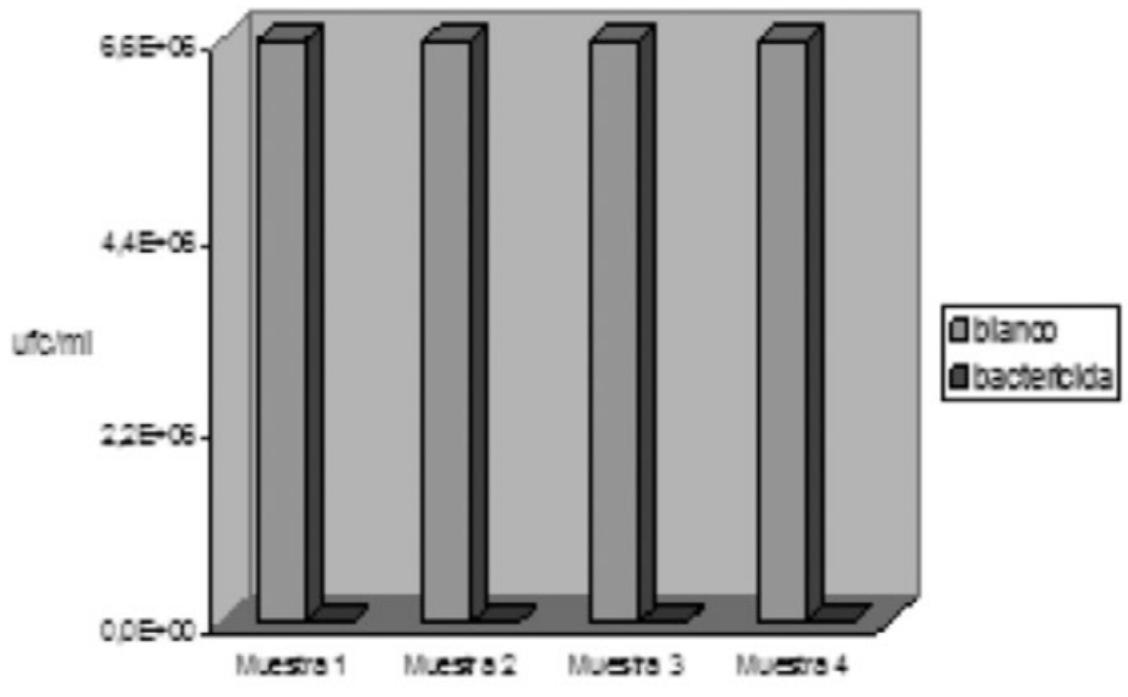

Figura 5. Número de ufc/ml en las muestras tratadas respecto al blanco, para el microorganismo Escherichia coli. 
En la Figura 6 se muestra a modo de ejemplo una placa Petri resultante de la inoculación del blanco con una suspensión de E. coli según el procedimiento descrito por la norma JIS. Se observa un importante crecimiento de ufc. Cada puntito blanco que se observa en la fotografía corresponde a una ufc. Tras observar la placa Petri podemos establecer que el mosaico vítreo sin ningún tratamiento no presenta propiedades bactericidas, ya que permite el crecimiento de las bacterias. En la Figura 7 se muestra a modo de ejemplo una placa Petri resultante de la inoculación de la Muestra 1 con una suspensión de E. coli según el procedimiento descrito por la norma JIS Z 2801. En este caso no se observan ufc, lo que significa que el tratamiento bactericida es eficaz y no sólo impide el crecimiento de bacterias sino también las elimina.

En la Tabla 1 se muestra el valor $\mathrm{R}$ obtenido para cada microorganismo y para cada material.

TABla 1. ACTIVIDAd ANTIMICROBIANA R y PORCENTAJE DE REDUCCIÓN DE BACTERIAS

\begin{tabular}{|l|c|c|c|c|}
\hline \multirow{2}{*}{ Muestra } & \multicolumn{2}{|c|}{$\begin{array}{c}\text { R (Actividad } \\
\text { Antimicrobiana) }\end{array}$} & \multicolumn{2}{c|}{ Reducción relativa (\%) } \\
\cline { 2 - 5 } & S. aureus & E. coli & S. aureus & E. coli \\
\hline 1 & 3,85 & 4,18 & 99,99 & 99,99 \\
\hline 2 & 4,18 & 4,18 & 99,99 & 99,99 \\
\hline 3 & 2,48 & 4,18 & 99,70 & 99,99 \\
\hline 4 & 2,63 & 4,11 & 99,80 & 99,99 \\
\hline
\end{tabular}

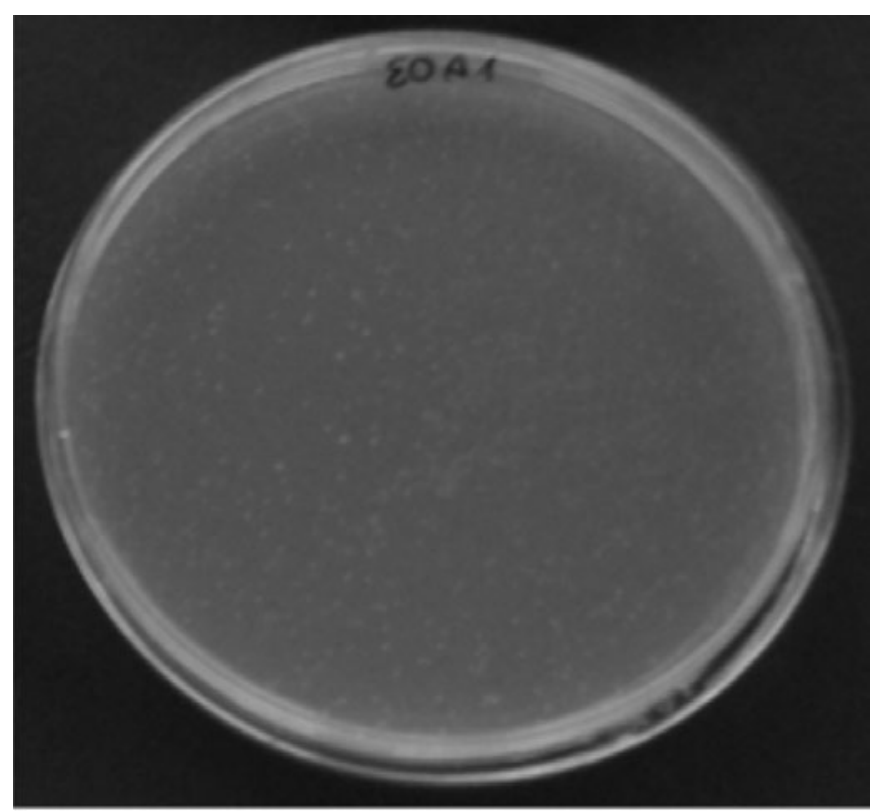

Figura 6. Blanco con E. coli (JIS Z 2801)
Todas las muestras ensayadas presentan una actividad antimicrobiana importante.

La norma indica que el parámetro $\mathrm{R}$, índice de eficacia bactericida, debe ser superior a 2 para ser considerado como tal. Según se observa en la Tabla 1, en todos los casos el valor obtenido es superior a 2. Esto significa una disminución del número de bacterias superior al 99,5\% frente a la población inicial.

La incorporación del compuesto bactericida estabilizado en una matriz evita o minimiza la formación de agregados de mayor tamaño y favorece la estabilidad del mismo durante el proceso de fabricación. Esto implica cantidades mucho menores para obtener un efecto bactericida y, por lo tanto, una reducción de los costes de fabricación.

\subsection{Mosaicos con propiedades fungicidas}

\subsubsection{APLICACIÓN DE VIDRIO DOPADO CON IMT}

Las propiedades fungicidas han sido inducidas mediante la aplicación de vidrio en polvo en el proceso de producción de los mosaicos.

La adherencia de los recubrimientos es muy alta y no se producen defectos, pudiéndose controlar la textura controlando las variables térmicas y el tamaño de partícula del polvo activo. Estos ensayos han permitido determinar el ciclo térmico óptimo para permitir un perfecto acoplamiento recubrimiento-soporte de vidrio.

La adherencia del recubrimiento no varía con el tiempo, y los ensayos de dureza al rayado y desgaste mecánico presentan resultados similares a los del mosaico vítreo tradicional.

En los ensayos preliminares de actividad fungicida se han inoculado esporas mezcladas con agar para fijarlas a las teselas. En la Figura 8 se ven los conidióforos -que son verdes, como en las colonias de moho en el queso- en la tesela inoculada (arriba) pero no en la tratada (debajo).

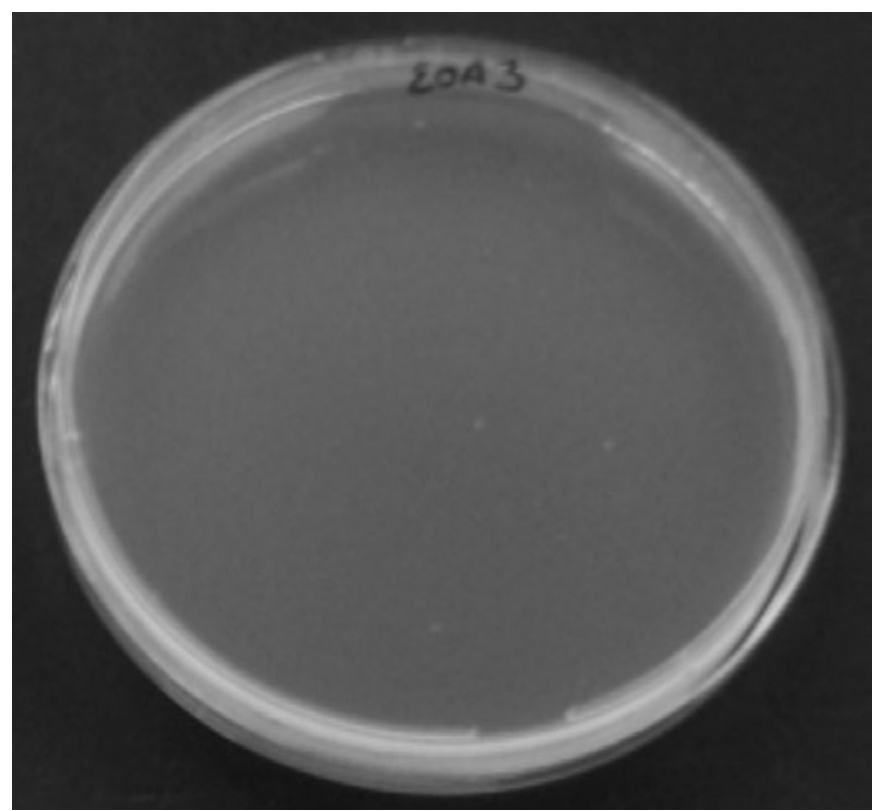

Figura 7. Muestra 1 con E. coli(JIS Z 2801) 
Este resultado preliminar confirmaría la actividad fungistática del vidrio dopado con iones metálicos, que inhibiría la adherencia de las esporas, pero no su capacidad fungicida. Los ensayos de actividad fungicida en función del tiempo y para varios tipos de cepas necesitan un proceso de optimización de parámetros. En cada tipo de sustrato a ensayar y en cada tipo de cepa utilizada hay que fijar las condiciones óptimas para asegurar la supervivencia de la cepa y comprobar la eficacia del producto.

\subsubsection{EFICACIA FUNGICIDA DEL VIDRIO DOPADO CON IMT}

Para comprobar la actividad fungicida del material se ha establecido una colaboración con el Grupo de Genética Molecular de Aspergillus del Centro de Investigaciones Biológicas del CSIC, el mayor centro de investigación dedicado al estudio de hongos en España, seleccionando el Aspergillus Nidulans (Figura 8) como agente patógeno, por las razones que se detallan a continuación.

Comparado con las bacterias, un hongo es un organismo superior, de una complejidad parecida a la de plantas y animales. Son organismos eucariotas, es decir, tienen células con núcleo y cromosomas. Por eso su estudio no es tan sencillo como el de las bacterias. Afortunadamente, ahora disponemos de algunos sistemas modelos, Saccharomyces cerevisiae y Aspergillus nidulans, cuyos genomas ya han sido secuenciados.

A los pacientes con defensas bajas [9] , Michael Rinaldi, de la Universidad de Texas, les llama "tubos de ensayo vivientes", vista la gran cantidad de patógenos que albergan. En ellos se ceban las micosis oportunistas, entre las que destacan las causadas por Aspergillus nidulans. Este agente patógeno estremeció a la opinión pública española en 1998, al infectar los quirófanos de dos hospitales y matar a varios pacientes. El hongo, presente en el polvo, se disemina cuando las obras en construcción remueven la tierra y lanzan sus esporas al aire. Se le achaca el $80 \%$ de las infecciones fúngicas sistémicas.
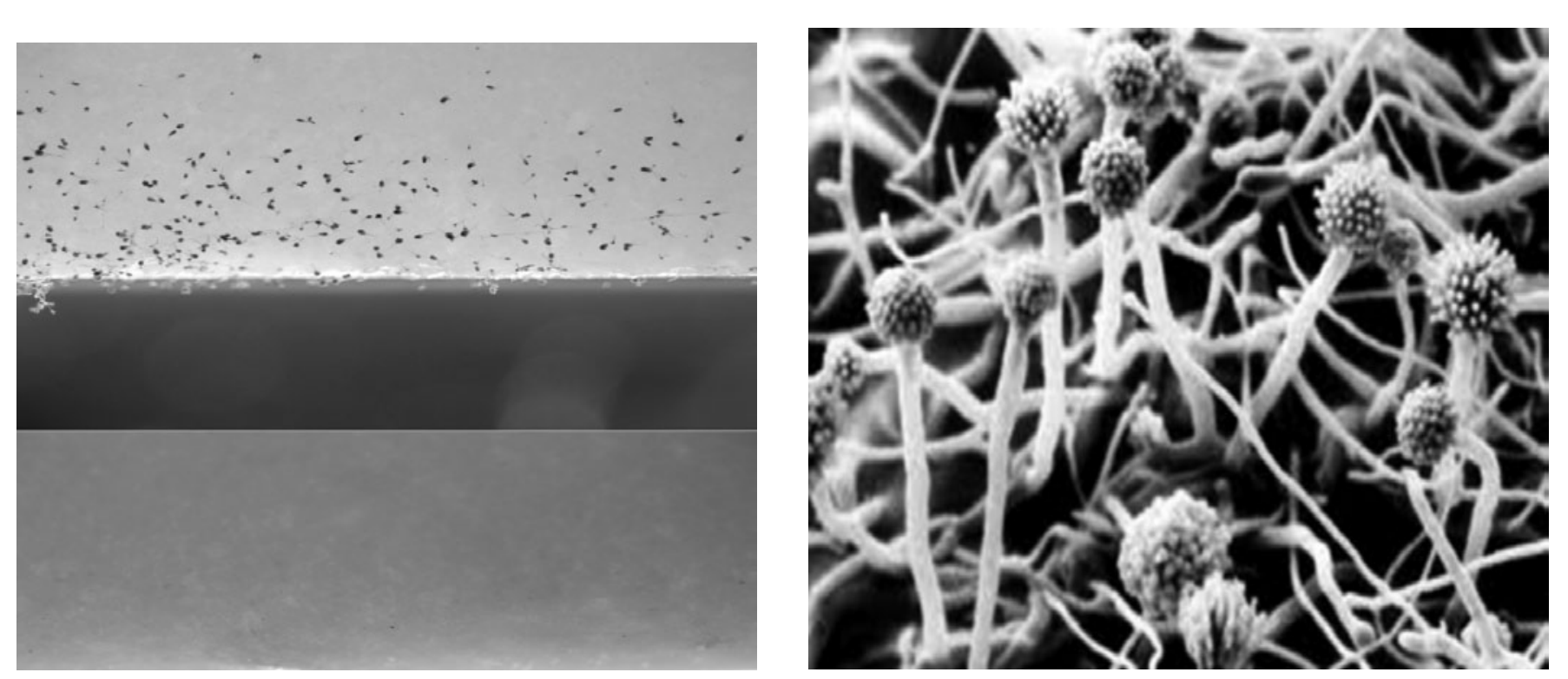

Figura 8. Tesela con conidióforos (arriba) sin tratamiento y tesela sin conidióforos con el tratamiento superficial (abajo). (derecha) Aspergillus Nidulans.

Se han ensayado dos tipos de vidrios conteniendo IMT y dos muestras de referencia recubiertas con $\mathrm{TiO}_{2}$ cristalizada en su forma de anatasa conteniendo IMT.

Se iñoculó una suspensión de conidios (densidad inoculada $4 \times 10$ conidios $/ \mathrm{mL}$ ) de una estirpe silvestre de Aspergillus nidulans en medio sintético con glucosa al $0.1 \%(\mathrm{w} / \mathrm{v})$ y urea $5 \mathrm{mM}$ como fuentes de $\mathrm{C}$ y N, donde el medio contenía $1 \%$ de agar. Se depositaron gotas de $0.1 \mathrm{~mL}$ sobre las teselas, se dejaron solidificar y se incubaron, dentro de una cámara húmeda, durante 3 días a $37^{\circ} \mathrm{C}$.

Como control se añadió a una de las muestras sin tratar benomil (2-Benzimidazol carbamato-(1-butilcarbamoilo) de metilo, C H N O ), un fungicida foliar sistémico de la familia

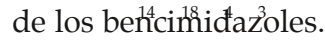

Para leer el ensayo hay que fijarse en los puntos oscuros (en realidad, verde oscuro) en el borde del agar. Los puntos negros son conidióforos que crecen sobre las hifas que han salido del agar y se han extendido sobre el recubrimiento (recuadro rojo). Es difícil fotografiar las hifas por la refringencia del vidrio, aunque por el color de (TiII a TiIV) se pueden distinguir por el brillo.

El resultado de los ensayos es el siguiente:

\begin{tabular}{|c|c|}
\hline MUESTRAS & RESULTADO \\
\hline Vidrio I & DESAPARECEN \\
\hline Vidrio II & DESAPARECEN \\
\hline Vidrio III & CRECEN \\
\hline Ti I & CRECEN \\
\hline Ti II & CRECEN \\
\hline Ti III & CRECEN \\
\hline Ti IV & CRECEN \\
\hline
\end{tabular}




\section{Tesela sin tratar Tesela sin tratar + Benomil}

\section{Tesela + VIDRIO I Tesela + VIDRIO II}

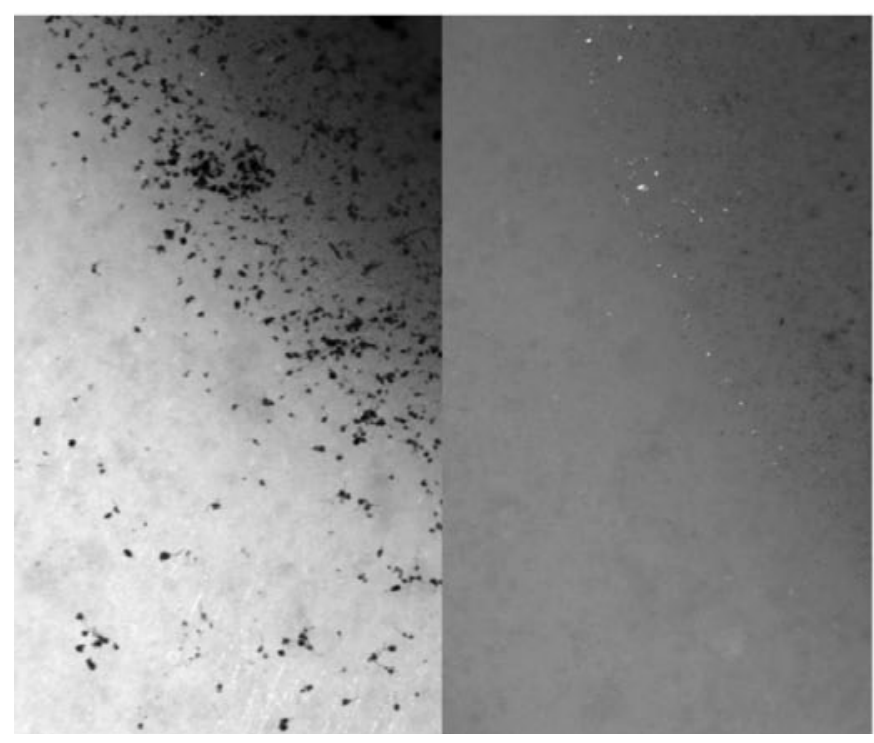

Figura 9. Superficies con los diferentes tratamientos aplicados.

Podemos concluir que las muestras I y II destruyen los hongos, no sucede así con el resto de las muestras ensayadas, Figura 9.

Por otra parte, las referencias de $\mathrm{TiO}_{2}$ no muestran efecto fungistático ni fungicida ya que en todas las muestras que lo contienen la colonia de Aspergillus Nidulans crece.

\section{CONCLUSIONES}

- Se ha obtenido un nuevo producto mediante la combinación de recubrimientos sobre mosaico vítreo con vidrios dopados con iones metálicos.

- Estos mosaicos presentan actividad bactericida contra bacterias gram negativo y gram positivo, frente a bacterias del tipo E. Coli y Staphylococcus aureus.

- El producto desarrollado en TOGAMA es bactericida en ausencia de luz UV, por tanto es adecuado tanto para interiores como para exteriores.

- Se han obtenido datos cuantitativos de eficacia antibacteriana, según la normativa internacional, JIS Z 2801, equivalente a la actual ISO 22196:2011.

- Los mosaicos recubiertos con vidrios dopado con IMT muestran además una importante actividad fungicida frente al Aspergillus nidulans.

- Se ha conseguido una aplicación superficial del compuesto, de forma que quedan integradas en la matriz vítrea de las teselas, y permanecen en su superficie.

- La suma de estos recubrimientos actúa de forma sinérgica exaltando las propiedades bactericidas y adicionando una actividad fungicida que dota al mosaico vítreo de una nueva funcionalidad de alto valor añadido y con excelentes perspectivas en diversos nichos de mercado como hospitales, clínicas, piscinas, spas y centros de masaje, oficinas públicas y ambientes húmedos en construcción pública y privada.

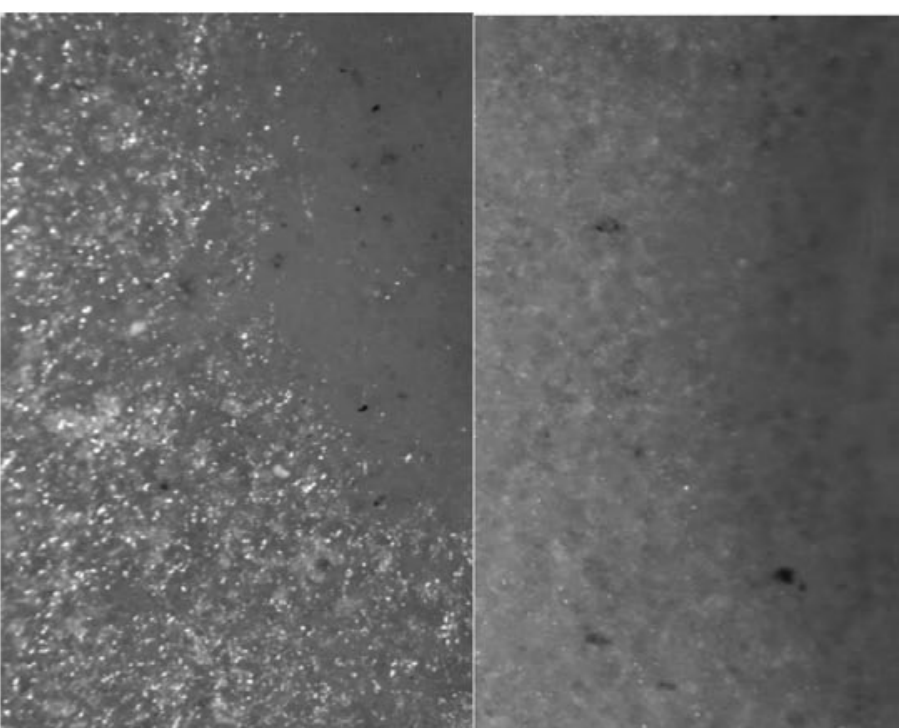

\section{AGRADECIMIENTOS}

Los autores de este trabajo agradecen a Miguel Angel Peñalva y Elena Reoyo del Grupo de Genética Molecular de Aspergillus del Centro de Investigaciones Biologicas del CSIC por los ensayos de actividad fungistática y fungicida. Asimismo, agradecemos la colaboración del Hospital La Plana de Villarreal, en particular al Director Gerente Dr. D. Javier Peñarrocha y a Dña. Silvia Pesudo, Jefa del Laboratorio del citado Hospital.

\section{BIBLIOGRAFÍA}

(1) Tichell, M.; Pascual, A.; Bakali, J.; Cordoncillo, E.; Escribano, P.; Carda, J. Desarrollo de vidrios cerámicos con propiedades bactericidas aplicados como esmaltes sobre azulejos cerámicos. Técnica cerámica 280, 48-52, 2000

(2) Jaquotot, P.; Campillo, A.; Reinosa, J.J.; Romero, J.J.; Bengochea, M.A. Esteban-Cubillo, A.; Santarén, J.; Aguilar, E.; Pina, R.; Pecharroman, C.; Moya, J.S.; Fernández, J.F. Desarrollo de esmaltes nanoestructurados multifuncionales. Bol. Soc. Esp. Ceram. 48(2), 95-8, 2009

(3) Angiletto, E. Riella, H.G. Cadore, J.C. Smania, A. Producción de vidrio de intercambio iónico para su uso en materiales cerámicos con propiedades bactericidas. En: Qualicer 2002: VII Congreso mundial de la calidad del azulejo y del pavimento cerámico III. Castellón: Cámara oficial de Comercio, Industria y Navegación, 2002, Pos 121-Pos 128

(4) Tucci, A. Nanetti, A. Malmusi, L. Timellini, G. Ceramic surfaces with microbiological action for healthcare buildings. CFI, Ceram. forum int., 84 (3), E47-E50, 2007

(5) Campbell A.L. Antimicrobial ceramic glazing composition, useful for manufacturing glazed ceramic substrate, comprises ceramic glaze base and antimicrobial composition comprising antimicrobial agent e.g. silver carbonate and zinc oxide, WO2008103621

(6) Matsumoto, A. Itou, S. Morita, T. Aihara, Y. Yamashita, R. Mizuno, H. Imai, S. Sugiyama, N. Tokushima, S. Ishida, S. Glass layered ceramic product. US7488442

(7) Adachi N.; Shiga M.; Ueno T.; Horiuchi S.; Machida M. Process for producing antibacterial glaze, antibacterial member, and process for producing the member. EP0808570

(8) Chen Z.; McHale J.M. Antimicrobial glaze and porcelain enamel via double layer glaze with high zinc content. US2009117173

(9) Rubio, V.; Experto del Centro Nacional de Biotecnología (CNB-CSIC),2000. http: / / www.elcultural.es / version_papel/CIENCIA/2767 / Oltimos_ avances_para_combatir_los_hongos_patogenos. 